\title{
Improving Healthcare Referral System Using Lean Six Sigma
}

\author{
Atif Alkinaidri' ${ }^{1}$, Hemaid Alsulami ${ }^{2}$, Ayman Al-Nafea1 ${ }^{1}$ \\ ${ }^{1}$ King Abdullah Medical City, Makkah, Saudi Arabia \\ ${ }^{2}$ Faculty of Engineering, King Abdulaziz University, Jeddah, Saudi Arabia \\ Email: ALKINAIDRI.A@kamc.med.sa, healsulami@kau.edu.sa
}

How to cite this paper: Alkinaidri, A. Alsulami, H. and Al-Nafea, A. (2018) Improving Healthcare Referral System Using Lean Six Sigma. American Journal of Industrial and Business Management, 8, 193 206.

https://doi.org/10.4236/ajibm.2018.82013

Received: January 10, 2018

Accepted: February 8, 2018

Published: February 11, 2018

Copyright $\odot 2018$ by authors and Scientific Research Publishing Inc. This work is licensed under the Creative Commons Attribution International License (CC BY 4.0).

http://creativecommons.org/licenses/by/4.0/

Open Access

\begin{abstract}
The World Health Organization considers the referral system, begun in 1978, to be one of the primary components of any medical system. Referral is the procedure of directing a patient to an appropriate specialist or agency. This research uses King Abdullah Medical City in Makkah, Saudi Arabia as a case study to explore using Lean Six Sigma as a way to improve healthcare referral system. King Abdullah Medical City received 16,807 referral requests in 2015, a $13.6 \%$ increase compared with 2014 . Over time, the process of referral unwieldy, making the process less efficient and effective. By addressing the application of Lean principles and Six Sigma methodology to improve the referral process, this study reveals implications for their use in the healthcare industry. Then DMAIC methodology was utilized to decrease the delay in physicians' response time to the referral system. After the Lean Six Sigma project was completed, a noticeable improvement in compliance to response times was achieved and sigma improved from 2.05 to 2.2 ; even greater improvement is expected after all of the long term recommendations have been applied.
\end{abstract}

\section{Keywords}

Improving Healthcare, Referral System, Lean, Six Sigma, Response Time

\section{Introduction}

A referral can be defined as a procedure to transfer a patient from a healthcare organization which does not have sufficient resources (such as facility, physicians, skills or equipment's) to another healthcare organization that has better level of services, facility, experts or equipment's. Hospital usually takes the decisions of Referral procedure based on several cases such as emergency case, more diagnostic or experts' opinions. The Ministry of Health (MoH) in Saudi Arabia 
offers three kinds of healthcare services as shown in Figure 1. Level one primary which is concern of providing the basic health services. The second level is Secondary care which concern of providing advances health services to patients. The third level is the tertiary, which deal with the complex cases that were transferred from the second level [1].

King Abdullah Medical City (KAMC) in Makkah city, Saudi Arabia became operational on August 2011 as a government hospital under the MoH with 550 beds; it is a multi-disciplinary and evidence-based patient care facility with a focus on oncology, neurosciences, advanced \& minimally invasive surgeries, organ transplantation \& Hajj critical care services. Customers are referral cases from the Makkah region, and the western coast. Services are free for citizens' patients and Umrah \& Hajj visiting patients.

KAMC received 16,807 referral requests in 2015 , a $13.6 \%$ increase compared with 2014. Over time, the process of referral from primary care to specialty clinics became unwieldy, making the process less efficient and effective. Consequently, there were delays in response to the referral beside there were incomplete documents of patients. In addition, patients were unsatisfied with the KAMC services.

This study aims to implement Lean Six Sigma methodology on the hospital referral processes to increase compliance of physicians' response time to the referral system. To fulfill the aim of the project the following objectives are targeted:

1) To examine how Lean Six Sigma can lessen delays in physician response time.

2) To improve the current referral system at KAMC.

\section{Lean}

Invented by the CEO of Toyota, TaiichiOhno, lean is a methodical approach that identifies and eliminates waste (and non-value-added activities) [2]. This can be achieved by continuous improvement and following with the production to the pull of the customer in pursuit of perfection [2]. TaiichiOhno based this system on the fact that human activity causes errors due to absence of value in the process, leading to seven types of "muda" or "waste" [2]. Lean was introduced at

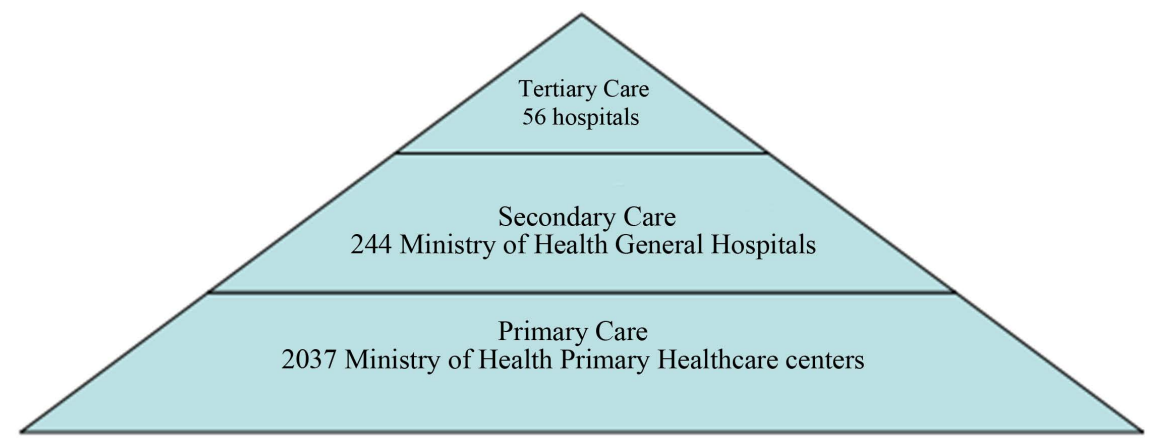

Figure 1. Levels of healthcare services in Saudi Arabia. 
Toyota in 1950, but became famous in the West in the 1980s [3]. Major companies consider lean principles one of the varied approaches to help a business remain in healthy competition to meet increased worldwide demand [4].

The Lean approach emphasizes the importance of reducing costs by eliminating non-value-added (NVA) activities and utilizing Lean tools as a method of sustaining and optimizing supply [4]. The crucial principle of a Lean supply chain is to generate a streamlined highly efficient system. This system results in finished products that can more successfully satisfy customer demand with a minimum level of waste [4]. The key principle of the Lean method is to eliminate all kinds of waste in developing a higher standard of operational production, producing at a reduced cost in a shorter time [3]. Hence, the core idea of lean is to maximize the customer value and eliminate waste. In short, lean aiming to provides customers with more value and less resources [3].

According to Mannon, Lean's philosophy is based on eliminating the seven types of waste including the following: 1) Overproduction: producing more than required, before being required; 2) Inventory: retaining extra inventory in all processes; 3) Extra processing steps: completing more work than necessary; 4) Motion: any unnecessary activity such as picking up or placing (including wasted walking); 5) Defects: repair and correction; 6) Waiting: awaiting data or approval in receiving supplies or any other equipment; 7) Transportationwasted effort in transporting any equipment or materials between processes or in/out of storage [5].

\section{Six Sigma}

The concept of Six Sigma theory offers an approach to problem solving and involves a strong organizational framework consisting of redesigning a product, which then results in the elimination of defects [6]. Six Sigma provides excellent quality, including a more efficient and lower cost service than its competitors [2]. It has rapidly gained popularity as it helps to implement overhead cost savings and efficiency [7]. Bob Galvin, the CEO of Motorola, was the first to launch Six Sigma in 1987 based on a suggestion by Bill Smith [8]. As a result of this, a new standard was adopted to reach 3.4 defects per million opportunities [8]. This new standard ensured that capital was not wasted and productivity was maintained; consequently, the company saved several billion dollars. Since then, many other companies around the world have adopted the same approach [8]. Such effective and maintainable approaches in establishing a competitive advantage and in achieving long-term targets provide a reduction in both of time and costs, and thus improve revenue enhancement [8].

The Six Sigma improvement technique is generally known under the acronym (DMAIC) which stands for the following processes: Define: "What is most vital to the business?" This includes defining what the problems are, including customers' needs and demands, that are mandatory to explore to determine requirements for the improvement [9]; Measure: "How are we progressing with 
the present process?" This involves assessing the process to be applied-data needs to be collected and then compared to the predicted state [9]; Analyze: "Identify what could be wrong with the present process" This includes analyzing data in order to determine what the major cause of the issue could be [9]; Improve: "What could be possibly applied to improve the process?" Here, the team initiates brainstorming to develop ideas to solve the problems and identify different variations in that process. The results at this point are then analyzed to determine whether the problems have been resolved or not. Further alterations are required if problems still persist [9]; the end step is Control: "How could performance be guaranteed in order to sustain improvements over time?" This means that the progress should be sustained so that no unanticipated or unwanted changes could occur. The process then should operate at the desired level of performance to make sure that the problem never re-exist [9].

DMAIC is an improvement methodology processes that help to identify the problem precisely and make the scope and objectives very clear [10]. Then analyze the data from the collected data to examine the root cause of the problem in order to provides a suitable solution. After that, it provides control system to prevent the problem to happen again [10].

\section{Why Lean Six Sigma}

The referral system in hospitals requires the interlinking of many mesosystems and includes both clinical and non-clinical staff. The published literature has a significant amount of evidence supporting the notion that human capital is the key factor to quality improvement and successful implementation. While most studies focus on investigating organizational culture and quality improvement in several areas, they do clarify that the motivation of the individual, the staff attitude towards quality problems and solutions, and the quality of teams to be the most frequently reported contextual factors [8] [9] [10]. Lean implements a strategic approach that involves staff within the process of continuously improving the quality of care in hospitals, thus diminishing errors and delays [11]. Furthermore, if Lean is simply understood and utilized by hospital staff, it can diminish various types of waste, which is a common issue within hospitals [12]. Most hospital supply chain systems acquire medical items that are managed by staff that do not have enough knowledge of the sensitivity of these medical items in regards to storage and distribution [13]. Because the success and quality of the healthcare industry mainly relies on human expertise, Six Sigma can also be useful, as it focuses on developing human skills, including training and communication. Overall, evidence suggests that Six Sigma is one of the ideal quality assurance strategies in the healthcare industry [14]. Both lean and six sigma have Strengths factors as can be seen in Table 1.

\section{Lean Six Sigma Practices in Healthcare}

Womack and Jones proposed how Lean can be implemented in healthcare and 
Table 1. Strengths of both lean and six sigma.

\begin{tabular}{|c|c|c|}
\hline & Lean & Six Sigma \\
\hline Theory & Eliminate waste & Reduce variation \\
\hline Objective & Deliver value to the customer & Deliver value to the customer \\
\hline Focus on & Value stream mapping & Variation in process (Problem focused) \\
\hline \multirow{2}{*}{ Assumptions } & $\begin{array}{l}\text { Improvement in waste removal } \\
\text { targeting business performance }\end{array}$ & $\begin{array}{l}\text { Reduction in the variation of all input } \\
\text { processes, improves system output }\end{array}$ \\
\hline & $\begin{array}{l}\text { Variable tiny improvements make a } \\
\text { better analysis system }\end{array}$ & Existence of the problem \\
\hline Goal & Increase speed \& efficiency & Improve quality with low cost \\
\hline
\end{tabular}

claim that understanding the patient journey is a fundamental primary step in their treatment [15]. They advised that Lean-thinking concepts developed in the field of industrial manufacturing and successfully implemented could also be implemented into the healthcare industry [13]. Therefore, to achieve satisfying customers' demands and in a more efficient way than competitors, it is vital for the healthcare system supply chain to continually develop their processes. Additionally, they must take part in continuous improvement processes as well as adopt competitive approaches [13].

In the final analysis, Six Sigma results include: 1) more capable employees 2) reduced defects 3) reduced cycle times 4) lower inventory levels 5) higher efficiency and lower costs [12]. Achievements in these areas ultimately lead to increased overall customer satisfaction and employee satisfaction as well as higher market share and greater profits [16].

\section{Case Study: KAMC Referral Process}

\section{Referral Process Overview}

The referral system is the cornerstone to support the relation between basic medical care and hospitals. The World Health Organization (WHO) has considered the referral system one of the primary medical system components since 1978 [17]. The referral is classified as "horizontal" when it occurs between units of the same institution and "vertical" when it occurs between units of different institutions.

For streamlining the referral process in order to ensure smooth operation, ease of communication, improved efficiency, and overall process effectiveness, the Ministry of Health $(\mathrm{MOH})$ developed the electronic referral system. Their aim was to automate the referral submission and approval process between government hospitals and related agencies. The referral requests (Figure 2) are submitted and classified based on their type (ER, life threatening, outpatient, and inpatient); the system also provides tracking and monitoring for status of the referral request online.

The coordination office reviews the case and transfers it to the related medical department to study the case; if the case is rejected, the reason for rejection must 


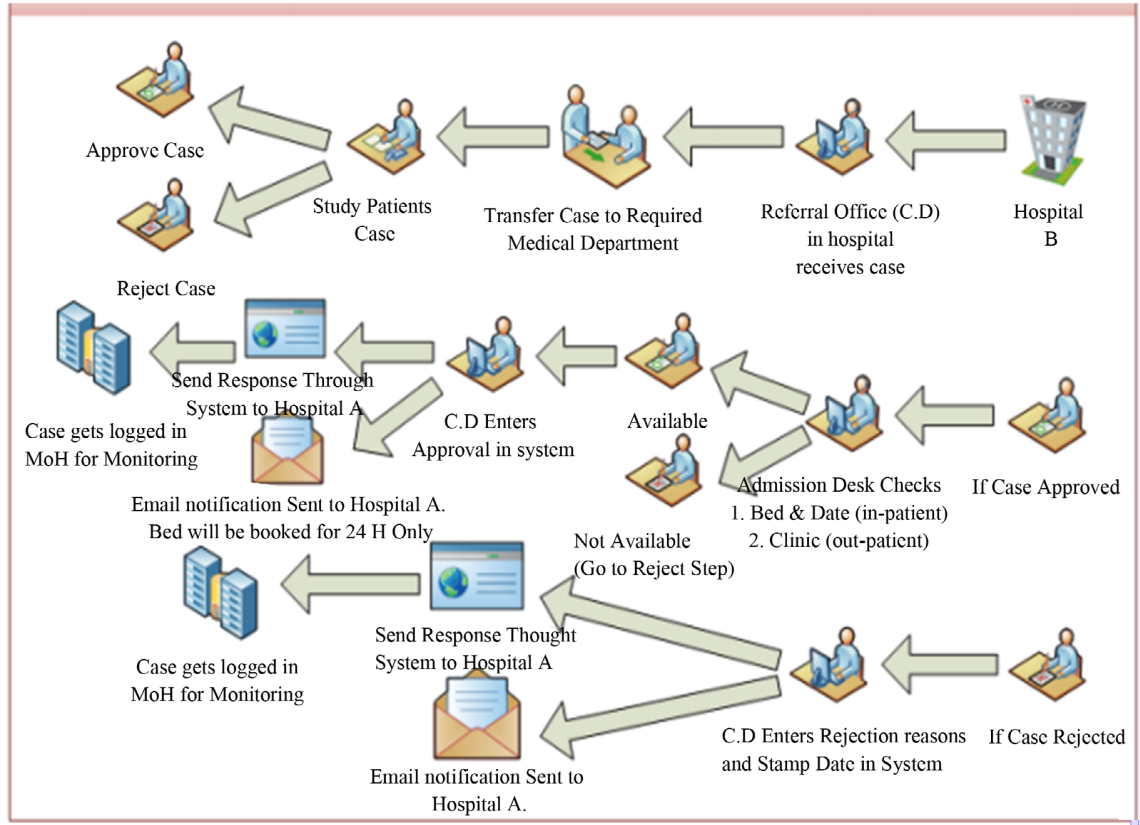

Figure 2. Patient referral request processing.

be given and the response sent to the submitting hospital, Hospital A. If the case is approved, the admission desk will check their availability to receive the case; i.e., whether a physician is available in the clinic, whether there is an available bed within the expected stay of the patient, etc. If there is availability, the case will be approved. Otherwise, it will be rejected and the reason for rejection will be selected and specified. This helps in reporting and in capacity planning. Hospitals with many rejected cases due to unavailability of beds will be prioritized for expansion or as first hospitals to be able to increase bed capacity when possible [18]. After the first approval is received, the medical department will be informed in the hospital to start the transfer process. The patient will be provided with the necessary information such as the hospital he/she will be transferred to, the transportation used for the transfer, the transfer date and time, etc. The treating doctor will be informed as well.

\section{LEAN and SIX-SIGMA Implementation}

\subsection{Define}

King Abdullah Medical City received 16,807 referral request in 2015, a 13.6\% increase compared with 2014 as shown in Figure 3. Over time, the procedure of referral from primary care level to specialty clinics has grown cumbersome and fragmented, impacting the efficiency of the process and the effectiveness of the system. Mainly, there are two parties that influence the response process: the coordination office and physicians. The time required for the coordination office to complete their activities (filling out the form, transferring it to the consultant, getting final confirmation) was less than $5 \%$ of all process timing. Based on that, the team was able to define the problem as coming from physicians, that is, the 


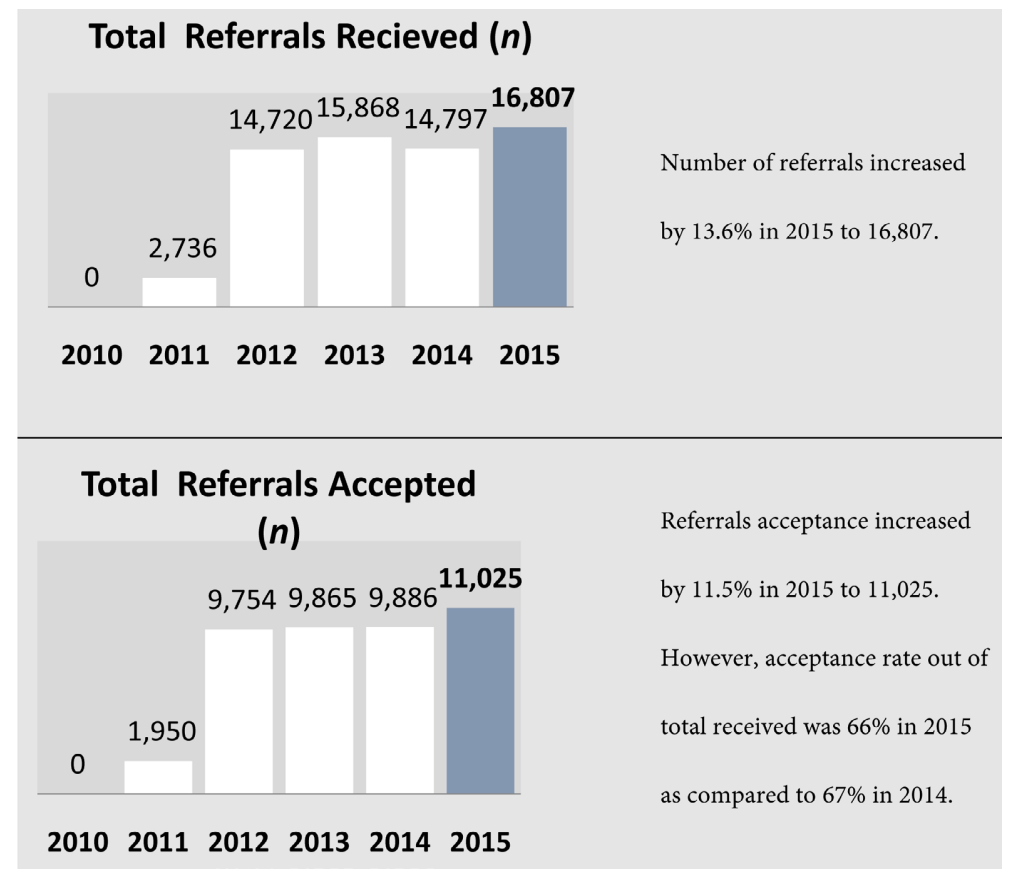

Figure 3. Total Referrals Received Vs Accepted data. Source: Ministry of Health (2015).

high proportion of late responses from the medical departments, which led to grumbling from other hospitals as well as patients and negatively affected patient safety and therefore the experience with KAMC. And this has also led it to raise this issue during the meetings with the hospitals in the region. The objective of the project then became to improve the physician response time to $95 \%$ for urgent requests and $90 \%$ for normal ones.

The next step in the process was to diagram a process map detailing the steps in the process, from receiving the referral request through the consult process (review, approval, and service) and the returned referral to the requester. This process map followed a standard SIPOC (supplier, inputs, process, outputs, and customers) analysis and provided the tools to identify appropriate measures and steps of value/nonvalue added activities [19], as shown in Table 2.

\subsection{Measure Phase}

Data were collected to pinpoint the problems and focus the improvement effort. At this phase, the yearly referrals accepted versus those received were tracked, as shown in Figure 2, and the responses of physicians during the period of JuneAugust 2016 were measured (Table 3 ) to determine whether the objectives were being met, that is, that the referrals were being processed and appointments were being made in a timely fashion. Timely fashion was then quantified; specifically, if the process took more than 4 hours for urgent cases and more than 24 hours for normal ones, it did not meet the criteria for "timely".

Physicians' response times for normal requests met the target $68 \%$ of the time, while response times for urgent requests met the target $79 \%$ of the time. In 
Table 2. SIPOC for Referral system.

\begin{tabular}{|c|c|c|c|c|}
\hline Suppliers & Input & Process & Output & Customers \\
\hline $\begin{array}{l}\text { MoH hospitals } \\
\text { private hospitals } \\
\text { E-halati system }\end{array}$ & $\begin{array}{l}\text { KAMC referral form } \\
\text { Consent form }\end{array}$ & & & \\
\hline Fax-Security forces & Personal data sheet & & & \\
\hline $\begin{array}{c}\text { Hospitals and } \\
\text { Military } \\
\text { Agencies like } \\
\text { government region, } \\
\text { police, medical } \\
\text { committees etc } \\
\text { By hand }\end{array}$ & $\begin{array}{c}\text { ID copy } \\
\text { Medical report } \\
\text { Radiological } \\
\text { Investigation reports } \\
\text { Laboratory } \\
\text { Histopathology reports }\end{array}$ & $\begin{array}{l}\text { Reception of Referral } \\
\text { either by e-halati/fax/hand }\end{array}$ & $\begin{array}{l}\text { Complete documents of referral } \\
\text { ready to be entered in medical plus }\end{array}$ & $\begin{array}{l}\text { Medical coordination staff } \\
\text { Referring }\end{array}$ \\
\hline $\begin{array}{c}\text { Medical } \\
\text { coordination staff }\end{array}$ & $\begin{array}{l}\text { Complete documents of } \\
\text { referral }\end{array}$ & $\begin{array}{l}\text { Entry into medical plus } \\
\text { referral system after } \\
\text { administrative verification } \\
\text { documents }\end{array}$ & $\begin{array}{l}\text { Referral pending in media plus } \\
\text { system }\end{array}$ & Medical coordination physician \\
\hline $\begin{array}{l}\text { Medical } \\
\text { coordination } \\
\text { physician }\end{array}$ & Referral system(software) & $\begin{array}{l}\text { Clinical review of } \\
\text { documents and refer to } \\
\text { appropriate specialty }\end{array}$ & $\begin{array}{l}\text { Case referred to other specialities } \\
\text { or rejected/more enquires }\end{array}$ & $\begin{array}{l}\text { Consultant physician/patient } \\
\text { relatives/referring hospital }\end{array}$ \\
\hline $\begin{array}{l}\text { Consultant } \\
\text { physician }\end{array}$ & Referral system(software) & $\begin{array}{l}\text { Response by concerned } \\
\text { speciality }\end{array}$ & $\begin{array}{c}\text { Medical rejection } \\
\text { More enquires } \\
\text { Admission-File opening }\end{array}$ & $\begin{array}{c}\text { Medical coordination staff } \\
\text { Bed management staff } \\
\text { Eligibility staff } \\
\text { Medical coordination physician }\end{array}$ \\
\hline $\begin{array}{l}\text { Medical } \\
\text { coordination staff }\end{array}$ & Response documents & $\begin{array}{l}\text { Reply received by medica } \\
\text { plus and conveyed to } \\
\text { referring authority if } \\
\text { rejected or more enquires. } \\
\text { In case of acceptance OPD } \\
\text { appointment/bet } \\
\text { reservation will be sent to } \\
\text { referring authority }\end{array}$ & $\begin{array}{l}\text { OPD appointment/bed } \\
\text { booking-rejection lette more } \\
\text { enquires letter }\end{array}$ & $\begin{array}{l}\text { hospital/physician/patients/ } \\
\text { patient relatives }\end{array}$ \\
\hline
\end{tabular}

Table 3. SIPOC for Referral system.

\begin{tabular}{|c|c|c|c|c|}
\hline WEEK & AVERAGE-URGENT CASE & URGENT KPI & AVERAGE-NORMAL CASE & NORMAL KPI \\
\hline Week 1 & $6: 39: 29$ & 4:00:00 & $27: 11: 18$ & 24:00:00 \\
\hline Week 2 & 6:00:58 & 4:00:00 & $35: 26: 25$ & 24:00:00 \\
\hline Week 3 & $5: 27: 56$ & 4:00:00 & $49: 49: 44$ & 24:00:00 \\
\hline Week 4 & 3:42:08 & 4:00:00 & $21: 12: 10$ & 24:00:00 \\
\hline Week 5 & 6:00:27 & 4:00:00 & $23: 32: 23$ & 24:00:00 \\
\hline Week 6 & $3: 53: 25$ & 4:00:00 & $20: 53: 51$ & 24:00:00 \\
\hline Week 7 & $4: 17: 01$ & 4:00:00 & $12: 08: 08$ & 24:00:00 \\
\hline Week 8 & $3: 07: 27$ & 4:00:00 & $11: 33: 33$ & 24:00:00 \\
\hline Week 9 & $4: 41: 45$ & 4:00:00 & $27: 23: 57$ & 24:00:00 \\
\hline Week 10 & $4: 56: 41$ & 4:00:00 & $18: 57: 31$ & 24:00:00 \\
\hline Week 11 & 4:02:49 & 4:00:00 & $18: 07: 22$ & 24:00:00 \\
\hline Week 12 & $5: 41: 29$ & 4:00:00 & $27: 14: 41$ & 24:00:00 \\
\hline Week 13 & $2: 45: 14$ & 4:00:00 & $16: 02: 35$ & 24:00:00 \\
\hline
\end{tabular}


addition, the process sigma was calculated as follows:

The total number of referrals received in the selected three months (JuneAugust) was 2452 cases.

The delayed cases numbered 689 , which is $28.1 \%$ of the total cases.

$$
\text { Yield }=(1-\text { DPO }) * 100 \rightarrow \text { Yield }=71.9 \%
$$

the process sigma is 2.05 .

\subsection{Analyze Phase}

The analyze phase utilized several steps to identify and confirm root causes of inefficiency (i.e., delays in response to the referral) to address process improvement. All paper referrals were collected and reviewed, and pathways were identified and analyzed. The outcomes for all referrals (i.e., incomplete, inappropriate, approved) were documented in a database. A fishbone diagram, or Cause-Effect diagram (Figure 4), was utilized to identify the causes of the delay, as well as a Pareto diagram (Figure 5).

The team was able to detect communication issues as a main cause for the delay, followed by system issues, which is more complex to deal with because there are other factors involved like outside support from $\mathrm{MOH}$. Drill-down analysis revealed delays in the referral process due to the following: 1) Availability Issues a) Lack of consultant b) Consultant out of town c) Consultant was busy in OR 2) Contact Issues a) Lack of personal contact b)No bravo available for referral c) No one answering the call 3) System Issues a) Internet connection problem b) PDF viewing problem c) Incomplete data (Reasons, X-ray ...) 4) Communications Issues a) Lack of internal communication between consultants b) No follow up from coordination office.

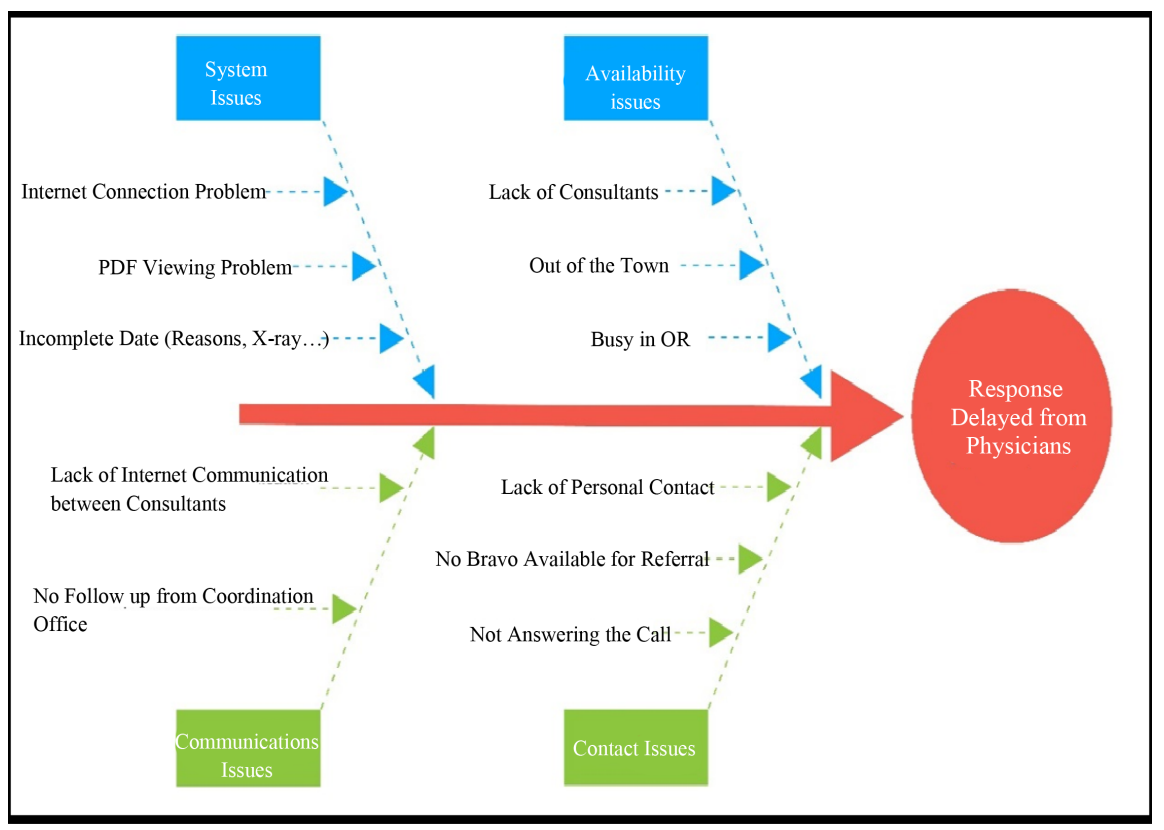

Figure 4. Fishbone analysis of reasons for delayed physician response to referrals. 


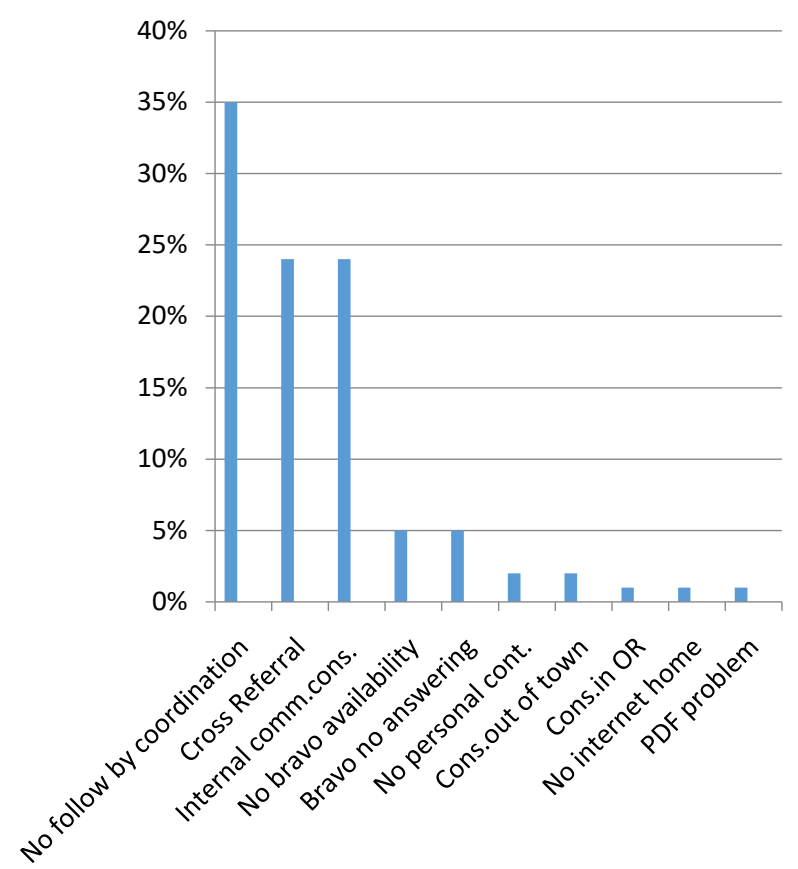

Figure 5. Pareto analysis for physicians delay.

In addition to conducting these analyses, the process data was combined with a map of the value-adding steps to help determine where waste could be removed. Two steps were identified to be eliminated (Figure 6 and Figure 7).

\subsection{Improve Phase}

In the improve phase, the results of the analyze phase were used to make tentative design change recommendations. These recommendations were then piloted, confirmed, and institutionalized in the control phase.

First, the team conducted a brainstorming workshop to explore possible solutions. After the solutions were reviewed and evaluated, the list of actions below was created, consisting of short and long term solutions:

1) Short term actions: a) Assign a Bravo number to each department for referral b) Send an SMS to the consultant as soon as the referral is incorporated into the system. c) Call consultant directly for all urgent cases, even utilizing the overhead calling system. d) Escalate to the head of the concerned department in case delay has exceeded the time limit for response. e) Communicate directly with the medical director in the event of failure to comply with previous attempts (after $24 \mathrm{Hrs}$ ). f) include the reason by the consultant (expectations and aim of the referral) on cross referral g) Request authority be given to the medical coordination physician to accept the straightforward cases if response time is exceeded. h) Communicate directly with the referral requester to complete the information for urgent cases. i) Call technical support to check all related issues and get them fixed.

2) Long term actions: a) Develop referral acceptance procedure to delegate authority. b) Formulate a standing committee for review and acceptance of 
Value Stream Mapping of Current Referral Processes

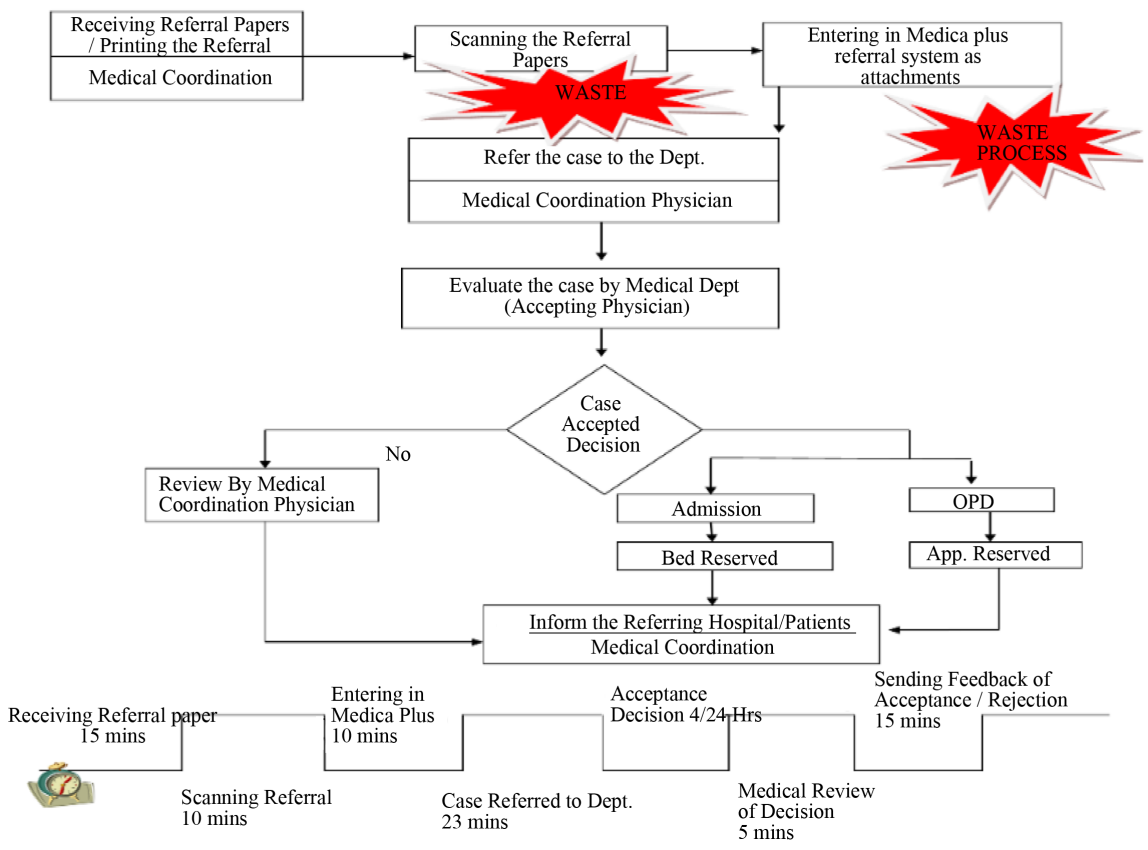

Figure 6. VSM of current referral system.

\section{Value stream mapping of future referral process}

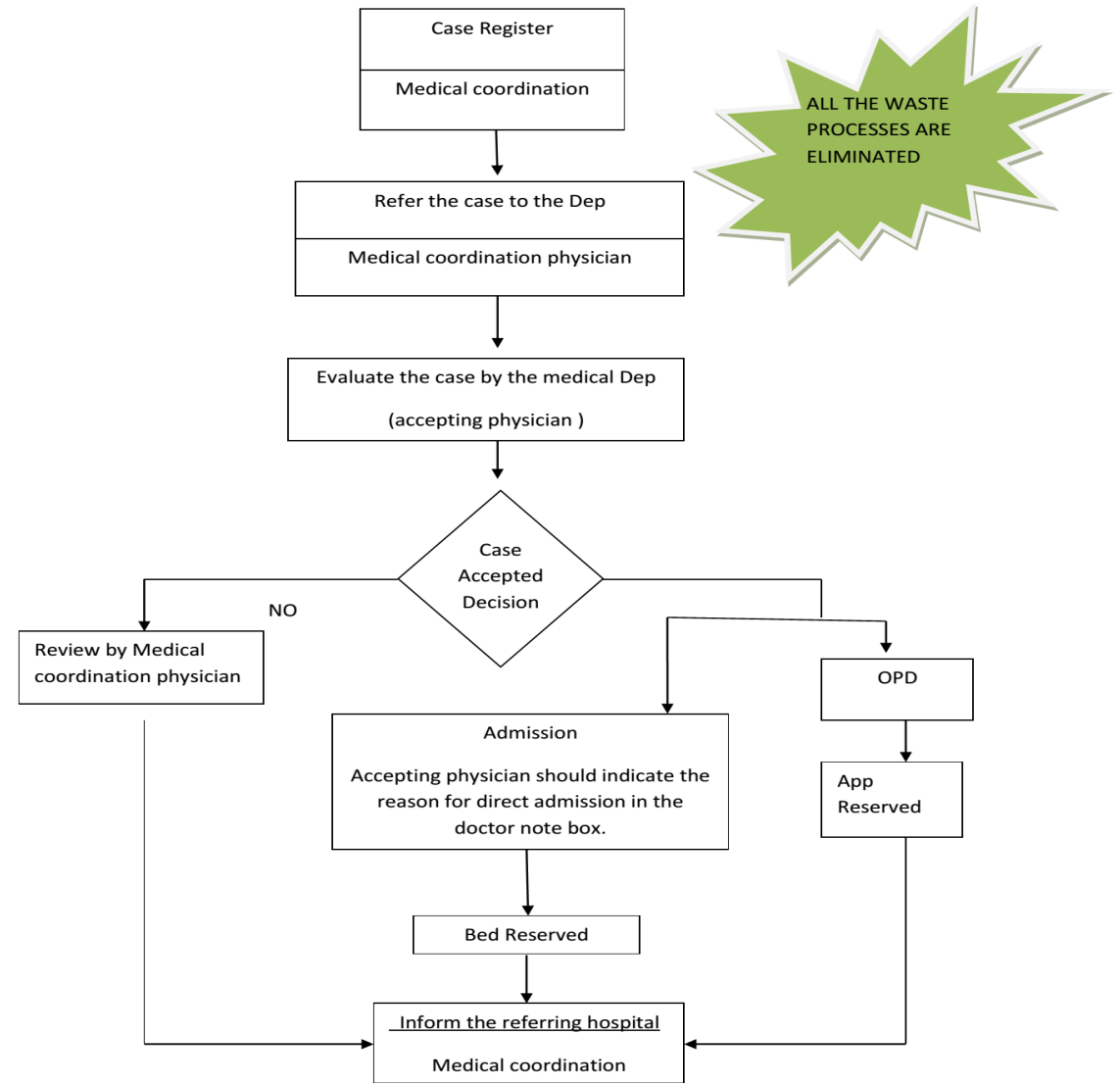

Figure 7. VSM of suggested referral system after waste elimination. 
referrals. c) Develop an E-Referral Mobile App. d) Request auto-escalation through the system.

The physician response time for normal requests met the target $72.5 \%$ of the time and for urgent requests $80.5 \%$. In addition, the process sigma was calculated as follows:

The total number of referrals received in the selected three months (Sep-Dec) was 4153 cases.

The delayed cases numbered 1012 , which is $21.5 \%$ of the total cases.

$$
\text { Yield }=(1-\text { DPO }) * 100 \rightarrow \text { Yield }=75.6 \%
$$

the process sigma is 2.2 .

\subsection{Control Phase}

Standardizing improved processes incorporates the Deming Plan-Do-Check-Act Cycle [20]. The monitoring, data analysis, and actions were performed by a coordination office. In the Plan-Do cycles, the following metrics were captured: physician response time for urgent and normal cases, and the number of escalated cases. A report was generated from the system monthly and presented at the monthly medical board meeting. The Check cycle utilized control charts from quarterly data to identify any undesirable patterns or trends. If an undesirable pattern or trend was identified, the coordination office, along with the concern department, did the following (Act cycle): discussed the problem area, improved breakdown in process and communication, and continued monitoring to ensure sustainability. In addition to that, awareness sessions were conducted to discuss the findings and agree on the actions.

\subsection{Conclusions and Recommendations}

In this study, a DMAIC approach was applied to streamline the internal referral process at KAMC. Process mapping, Pareto charting, and a cause-and-effect diagram are the tools that were used to analyze and solve the problem. A slight improvement was made in compliance to response time (4 hours for urgent cases and 24 hours for normal ones) and the number of urgent cases that experienced delayed physician response was reduced by $2 \%$ and the number of normal cases that experienced this was reduced by $5 \%$. In addition, more improvements are expected after implementation of the long-term recommendations. Physicians and department heads were generally positive about the intervention and liked the new communication rhythm and escalation process. Though hospital had attempted to improve the referral process through the application of recommended practices many times before, no significant differences had been noticed. Success in this instance seems to be related to the systematic, data-driven Six Sigma approach used by the team.

As the research study showed improvement in response rate, it is recommended that KAMC management accelerate the long-term action implementation to maximize the benefit of this project and achieve a better response rate. In 
addition, to keep the response rate high, it is recommended that: a) adequate and ongoing awareness and training facilities be provided to the related staff $b$ ) a reward system or some other such system be implemented to increase motivation, which is crucial for continuous improvement c) a dashboard be created for monitoring the agreed KPI's and taking proper action on the spot to overcome any difficulties.

Finally, as the study shows, implementing lean six sigma can lead to a significant improvement in healthcare services. It is highly recommended that hospitals begin to use lean six sigma programs to build a culture and a foundation to implement improvement projects. The lean six sigma can be used to improve the appointments system, patient accommodations, check-in processes, and discharge processes. In addition, it can be implemented in the pharmacy and laboratory processes.

\section{References}

[1] Alkhamis, A. (2012) Health Care System in Saudi Arabia: An Overview. Eastern Mediterranean Health Journal, 18, 1078-1080.

[2] Karim, A. and Arif-Uz-Zaman, K. (2013) A Methodology for Effective Implementation of Lean Strategies and Its Performance Evaluation in Manufacturing Organizations. Business Process Management Journal, 19, 169-196.

[3] Bossert, J. (2003) Lean and Six Sigma Synergy Made in Heaven. Quality Progress, 36.

[4] Burghall, R., Grant, V. and Morgan, J. (2014) Lean Six Sigma Business Transformation for Dummies. John Wiley \& Sons, USA.

[5] Mannon, M. (2014) Lean Healthcare and Quality Management: The Experience of ThedaCare. The Quality Management Journal, 21, 7-10.

http://search.proquest.com.ezproxy.brighton.ac.uk/docview/1503666135?accountid $\equiv 9727$

[6] De Koning, H., Verver, J.P., van den Heuvel, J., Bisgaard, S. and Does, R.J. (2006) Lean Six Sigma in Healthcare. Journal for Healthcare Quality, 28, 4-11.

[7] Proudlove, N., Moxham, C. and Boaden, R. (2008) Lessons for Lean in Healthcare from Using Six Sigma in the NHS. Public Money \& Management, 28, 27.

[8] Galganski, C.J. and Thompson, J.M. (2008) Six Sigma: An Overview and Hospital Library Experience. Journal of Hospital Librarianship, 8, 133-144.

[9] Gauss, C. and Shewhart, W. (1920) The History of Six Sigma. http://www.isixsigma.com/new-to-six-sigma/history/history-six-sigma/

[10] Powell, A.E., Rushmeer, R.K., Davies, H.T.O. and NHS Quality Improvement Supply Chain Otland (2009) A Systematic Narrative Review of Quality Improvement Models in Health Care. NHS Quality Improvement Supply Chain.

[11] Coffin, C. (2013) The Continuous Improvement Process and Ergonomics in Ultrasound Department. Radiology Management, 35, 22-25.

[12] Nicolay, C., Purkayastha, S., Greenhalgh, A., Benn, J., Chaturvedi, S., Phillips, N. and Darzi, A. (2012) Systematic Review of the Application of Quality Improvement Methodologies from the Manufacturing Industry to Surgical Healthcare. British Journal of Surgery, 99, 324-335.

[13] Varkey, P. and Kollengod, A. (2011) A Framework for Healthcare Quality Im- 
provement in India: The Time Is Here and Now. Journal of Postgraduate Medicine, 57, 237-241. https://doi.org/10.4103/0022-3859.85222

[14] Impellizzeri, F., Bizzini, M., Leunig, M., Maffiuletti, N. and Mannion, A. (2009) Money Matters: Exploiting the Data from Outcomes Research for Quality Improvement Initiatives. European Spine Journal, 18, S348-S359. https://doi.org/10.1007/s00586-009-0929-5

[15] Cavalheiro, L., Caserta Eid, R., Talerman, C., Prado, C., Gobbi, F. and Andreoli, P. (2014) Design of an Instrument to Measure the Quality of Care in Physical Therapy. Health Economics and Management, 13, 260-268.

[16] Paper, W. (n.d.) Pursuing Perfection in Healthcare with Six Sigma. White Paper, SIXSIGMA QUALTEC 2006, 1-8.

[17] Center for Innovation in Quality Patient Care (n.d.) http://www.hopkinsmedicine.org/innovation quality patient care/areas expertise/ lean sigma/about/

[18] Welch, J. (n.d.) What Is Six Sigma? http://www.isixsigma.com/new-to-six-sigma/getting-started/what-six-sigma

[19] Smith, B., Galvin, B., Bossidy, L., Welch, J., Shewhart, W. and Deming, E. (1993) General History of Six Sigma \& Continuous Improvement.

http://www.sixsigmatrainingfree.com/general-history-of-six-sigma--continuous-im provement.html

[20] Overland, D. (2011) The Buzz around Lean Six Sigma at Hospitals.

http://www.fiercehealthcare.com/story/buzz-around-lean-six-sigma-hospitals/2011$\underline{10-27}$ 